\title{
Model calculations on the use of mobile and stationary units for wood pellet production
}

\author{
J. SZENDREI ${ }^{1}$, G. GRASSELLI², B. KOCSI ${ }^{3}$, I. BUDAI ${ }^{4}$, E. SZÜCS ${ }^{5}$ \\ ${ }_{1}^{1}$ Debreceni Egyetem Műszaki Kar, szendrei.janos@eng.unideb.hu \\ 2 Debreceni Egyetem Műszaki Kar, grasselli@eng.unideb.hu \\ ${ }^{3}$ Debreceni Egyetem Műszaki Kar, kocsi.balazs@inf.unideb.hu \\ ${ }^{4}$ Debreceni Egyetem Műszaki Kar, budai.istvan@eng.unideb.hu \\ 5 Debreceni Egyetem Műszaki Kar, edit@eng.unideb.hu
}

Abstract. This paper presents the model calculations made for supporting the decision making of different technology alternatives. Base cases were A) use of a mobile pelletizer and B) using pellet factories at fixed locations for the production of a new product, sheep wool pellets. Calculations were made for three alternatives for each base case. The results of the model were used to examine the energy, time and cost criteria of the alternatives. Based on the given preliminaries, results of the model calculations supported the recommendation to choose case B) for further technology management and supply chain management decisions.

\section{Introduction}

This study was intended to support the decision on mobile and stationary pelletizing of sheep wool. Sheep wool pellets are a new eco-product in Europe and the technology as well as supply chain is in the planning and testing phase. The model calculations were used in the implementation of the CIP Eco-innovation project [1] "Value4Wool - Market Umbrella for the utilisation of low grade grease sheep wool as organic soil amendment and fertiliser" ${ }^{1}$. The results provided a basis to the decision whether to develop and operate a mobile pelletizer for sheep wool pelletizing or allocate the resources to other tasks in the project, cooperating with existing pelletizing units within the project area.

As regards the new product, base of all technologies to produce sheep woolpellets is to collect sheep wool, pelletize the material and distribute the product. Sheep woolpellets (Figure 1a) possess several beneficial features as ecological fertilizer [3]:

- ecological multi-functional fertilizer with long-term effect (up to 10 months)

- $100 \%$ renewable, without extraneous additives and chemicals

- soil loosening by swelling effect and water storage (up to 3.5 times of its own weight) in the soil

- good manageability through point by point and low-loss dosage under or around the root balls

- fertilizing function in combination with humification

\footnotetext{
${ }^{1}$ Hereinafterreferredtoas ,the project”.
} 
- profound maintenance of soil biology through a continuous nutrient and moisture regime

- remedy against acidification trends in soils

The sheep wool pellet swell strongly in the soil and can take up water by 3.5 times of their own weight (Figure $1 \mathrm{~b}$ )and store that sustainably. An additional water reservoir is therefore available for the plant. The following photo The following photo shows the swelling of sheep wool pellets after water addition. Both test tubes were filled previously with an equal volume of pellets.

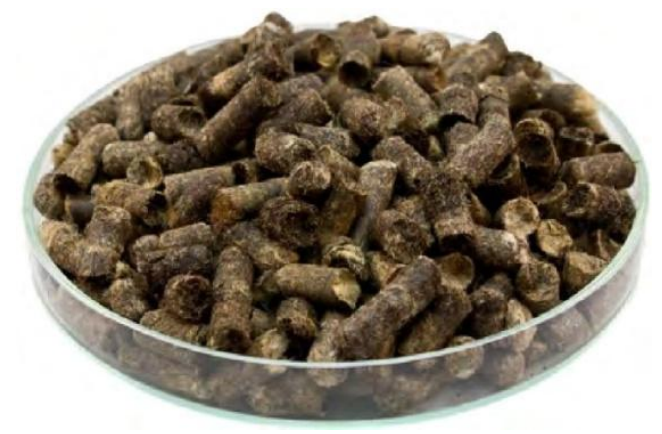

a)

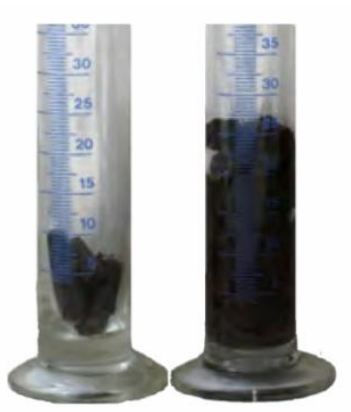

b)

Figure 1. a) Sheep wool pellets; b) swelling effect of sheep wool pellets by adding water

The authors'goal was to elaborate a model approach to help the decision-making by pointing out which conditions support the application of a mobile pelletizer and which conditions are the reasons to use existing pellet factories instead of the mobile unit. Decisive criteria were the energy, time and cost characteristics of the different model alternatives.

This paper gives a concise overview of the concept, the preliminaries and the outcomes of the model calculations.

\section{Model calculations}

\section{Base cases}

The concept of the model describes the (simplified) supply chain of sheep wool pellets as organised by a Chain Operator (CO), consisting of Wool Traders (WT), who collect the wool from the sheep breeders, a Mobile Pelletizer (MP) or Pellet Factories (PF) (which have the capacity to produce wool pellets) and Distributors (D) (who sell the wool pellets to farmers).

The model examines two cases.

Case A - use of a mobile pelletizer

The chain operator (CO) buys wool from wool traders (WTs), and sends to them a mobile pelletizer (MP) which pelletizes the wool at their sites. The CO sends the pellets by trucks to the distributors (Ds). After visiting each WT, the MP returns to the CO.

Case B - pellet factories at fixed locations 
The chain operator (CO) buys wool from wool traders (WTs), and sends the wool bales by trucks to pellet factories (PFs) which pelletize the wool at their sites. The CO sends the pellets by trucks to the distributors (Ds).

Examination of the two cases involved the energy, time and costs of

- investing in a mobile pelletizer (MP), moving it and producing pellets with it, and then moving the pellets to the distributors (Ds) (Case A);

- moving the wool bales, producing pellets with pellet factories (PFs) and moving the pellets to the distributors (Ds) (Case B).

Aim of model calculations was to examine the energy, time and costs involved in the implementation of Case A and Case B under different preliminaries, in order to help define the criteria that are decisive when choosing between the two cases.

After setting up the underlying model concept, preliminaries for the model frames were derived from the project's workplan [1], as well as coefficients used in the Life Cycle Analysis conducted during the project[2].

\section{Model background}

The project workplan's sheep wool pellets selling concept [1] outlines the amounts of pellets to be produced as shown in Table 1.

\begin{tabular}{|l|l|l|l|l|l|}
\hline Amounts/capacities & $\begin{array}{l}\text { Base unit } \\
\text { (Country 1) }\end{array}$ & mobile unit & $\begin{array}{l}\text { Fixed unit } \\
\text { (Country 2) }\end{array}$ & $\begin{array}{l}\text { Fixed unit } \\
\text { (Country 3) }\end{array}$ & total \\
\hline $\begin{array}{l}\text { capacity on 8 hour } \\
\text { shift period }\end{array}$ & 400 & 1000 & 2000 & 1000 & \\
\hline 1 post project year & 400 & 1000 & & & 1400 \\
\hline 2 post project year & 800 & 1000 & 800 & & 2600 \\
\hline 3 post project year & 800 & 1000 & 2000 & & 3800 \\
\hline 4 post project year & 800 & 1000 & 2000 & 500 & 4300 \\
\hline 5 post project year & 800 & 1000 & 4000 & 1000 & 6800 \\
\hline
\end{tabular}

Table 1. Anticipated sheep wool pellet amounts (tons per year) in the post-project years[1]

\section{Model alternatives}

Preliminary data for the wool pellet supply chain model were the data on the investment of a mobile unit (calculated with $38900 €$ material costs and 11 months of completion), pellet production ( $\sim 1000 \mathrm{t} / \mathrm{yr}$ both with mobile unit and fixed units), transport of mobile unit (300 km in average), raw wool transport (100 km in average) and pellet transport (200 km in average). 
Besides the main data, assumptions were made regarding the size and number of participants in projected future clusters.

\begin{tabular}{|c|c|c|c|c|c|c|c|}
\hline \multirow{2}{*}{\multicolumn{2}{|c|}{ Cluster sizes }} & \multicolumn{3}{|c|}{$\begin{array}{l}\text { Case } \\
\text { - use of a mobile pelletizer }\end{array}$} & \multicolumn{3}{|c|}{$\begin{array}{l}\text { Case } \\
\text { - pellet factories at fixed } \\
\text { locations }\end{array}$} \\
\hline & & "S" & "M" & "L" & "S" & "M" & "L" \\
\hline Participants & abbr. & \multicolumn{3}{|c|}{ Number of participants } & \multicolumn{3}{|c|}{ Number of participants } \\
\hline Wool Trader & WT & 3 & 6 & 15 & 3 & 6 & 15 \\
\hline Mobile Pelletizer & MP & 1 & 1 & 1 & $\mathrm{X}$ & $\mathrm{X}$ & $\mathrm{X}$ \\
\hline Pellet Factory & $\mathrm{PF}$ & $\mathrm{X}$ & $\mathrm{X}$ & $\mathrm{X}$ & 1 & 2 & 4 \\
\hline Distributor & $\mathrm{D}$ & 4 & 8 & 10 & 4 & 8 & 10 \\
\hline Total participants & & 8 & 15 & 26 & 8 & 16 & 29 \\
\hline
\end{tabular}

Table 2. Number of participants in projected future cluster sizes

\section{Model activities}

Like the number of supply chain participants, their average distances for transport operations had also to be determined. Based on the average distribution distance data of the Sheep Wool Pellets' Life Cycle Analysis[2], the assumption was made that the wool traders (WTs) that are fewer in number than distributors (Ds) are located more distant to each other. Pellet Factories (PFs), on the other side, are surrounded by WTs, thereby having smaller distance from them for wool transport. With growing cluster sizes and participant numbers, average distances lessen to an extent, due to a more even spatial allocation. Distributors, having a greater number than the other participants, are more or less evenly dispersed, the average distribution distances were deemed therefore as not altered by cluster sizes.

\begin{tabular}{|c|c|c|c|c|c|}
\hline \multirow{2}{*}{ Transport Distances } & \multirow{2}{*}{ Case } & \multirow{2}{*}{ avg. } & \multicolumn{3}{|c|}{ Cluster sizes } \\
\hline & & & "S" & "M" & "L" \\
\hline $\begin{array}{llll}\text { Average Transport } & \text { Distance } & \text { of } & \text { the } \\
\text { Mobile Pelletizer } & & & \end{array}$ & A & 300 & 320 & 300 & 280 \\
\hline $\begin{array}{lll}\text { Average } & \text { Distance } & \text { for } \\
\text { Wool Transport } & & \end{array}$ & B & 100 & 120 & 100 & 80 \\
\hline $\begin{array}{lll}\text { Average Distribution } & \text { Distances } & \text { for } \\
\text { Sheep Wool Pellets } & & \end{array}$ & A, B & 200 & 200 & 200 & 200 \\
\hline
\end{tabular}

Table 3.Average distances for transport operations (in $\mathrm{km}$ ) in projected future cluster sizes 
Assumed values were furthermore that one Wool Trader owns $300 \mathrm{~kg}$ wool and that Distributors have no limits on amounts of pellets to sell.

This way, the wool amounts to be processed match the planned production volumes:

\begin{tabular}{|l|l|l|l|}
\hline \multirow{2}{*}{ Amounts and capacities } & \multicolumn{3}{l|}{ Cluster sizes and years } \\
\cline { 2 - 5 } & "S" & "M" & "L" \\
\cline { 2 - 5 } & 1 & 2 & 5 \\
\hline Wool amounts & 900 & 1800 & 4500 \\
\hline Capacity of fixed unit(s) & 800 & 1800 & 4800 \\
\hline Capacity of mobile unit & 1000 & 1000 & 1000 \\
\hline
\end{tabular}

Table 4. Average wool amounts to be processed (in tons) in projected future cluster sizes

The assumption was made that the planned 2000 t/year capacity fixed unit (Table 1) will reach half production capacity in the second post project year. Assuming operation from the second half of the second year, the new stationary unit could add 1000 tons to the existing 800 tons capacity.

\section{Model preliminaries - summary}

Beside the $300 \mathrm{~km}$ average transport distance of the mobile pelletizer set as preliminary data for the wool pellet supply chain model, base data of the transport of the mobile pelletizer were also determined. These were used for wool and pellet transports as well. The base values in the following table match the data of the Life Cycle Analysis[2].

\begin{tabular}{|l|l|l|}
\hline Base data & unit & base value \\
\hline Total weight of truck & $\mathrm{t}$ & 7,5 \\
\hline Emission category & - & EURO-5 \\
\hline Total max. load & $\mathrm{kg}$ & 4000 \\
\hline Total actual load & $\mathrm{kg}$ & 2000 \\
\hline Diesel energy consumption for actual load & $\mathrm{l}$ & 14,6 \\
\hline Diesel emission pro l & $\mathrm{kg} \mathrm{CO} / \mathrm{l}$ & 3,174 \\
\hline Diesel emission pro km & $\mathrm{kg} \mathrm{CO} / \mathrm{km}$ & 0,463404 \\
\hline Diesel emission pro $\mathrm{km}$ and $\mathrm{t}$ & $\mathrm{kg} \mathrm{CO} / \mathrm{tkm}$ & 0,231702 \\
\hline speed & $\mathrm{km} / \mathrm{h}$ & 50 \\
\hline Cost & $€ / \mathrm{km}$ & 1,54 \\
\hline Average distance & $\mathrm{km}$ & 300 \\
\hline
\end{tabular}


Table 5. Base Data for Transport Expenses[2]

As a next step, energy, time and cost efforts of the Mobile Unit's transport can be derived from the above data. Table 7 lists specific values for energy, time and cost expenditures, calculated on different bases.

\begin{tabular}{|l|l|l|}
\hline Criteria & unit & base value \\
\hline Unit values of transport (for 1 ton for 100 km distance) & \multicolumn{2}{|l|}{} \\
\hline Energy & kg CO2 & 23,1702 \\
\hline Time & h & 2 \\
\hline Cost & $€$ & 38,5 \\
\hline
\end{tabular}

Table 6. Average Transport Expenses: Energy, Time and Cost

Data for the investment of a mobile unit are calculated with $38900 €$ material costs and 11 months of completion, according to the project's workplan. With the work efforts of 3 employees and with the budgeted average personal costs of the coordinating partner of the project (to whom the task was reallocated), this meant a $€ 179119$ investment cost. Based on the time calculated for labour, manufacturing of the mobile unit also involves a certain amount of energy use, which was calculated with a low estimate of an hourly $3 \mathrm{~kW}$ energy consumption and 0,6826 $\mathrm{kg} \mathrm{CO} \mathrm{CO}_{2}$ per $\mathrm{kW}$ electric energy for the machines.

\begin{tabular}{|l|l|l|}
\hline Investment of Mobile Unit & unit & base value \\
\hline Energy & $\mathrm{kg} \mathrm{CO} 2$ & 11894 \\
\hline Time & $\mathrm{h}$ & 5808 \\
\hline Cost & $€$ & 179119 \\
\hline
\end{tabular}

Table 7. Investment Expenditures of a Mobile Unit: Energy, Time and Cost

Furthermore, base data for sheep wool pellet production were determined for both the planned mobile and the already eyistingstationary pelletizing presses (factories).

\begin{tabular}{|l|l|l|}
\hline Base data & unit & base value \\
\hline Total pellets/total wool processed & $\mathrm{t} / \mathrm{t}$ & 0,83 \\
\hline Total pellets per hour & $\mathrm{t} / \mathrm{h}$ & 0,50 \\
\hline Total pellets per year & $\mathrm{t}$ & 1008 \\
\hline
\end{tabular}

Table 8. Base Data for Pellet Production

Rooted on the base data, the following energy, time and cost values can be calculated.

\begin{tabular}{|l|l|l|}
\hline Criteria & unit & base value \\
\hline Total values of production (for a year) & & \\
\hline
\end{tabular}




\begin{tabular}{|l|l|l|}
\hline Energy & $\mathrm{kg} \mathrm{CO}_{2}$ & 263169 \\
\hline Time & $\mathrm{h}$ & 2016 \\
\hline Cost & $€$ & 161280 \\
\hline
\end{tabular}

Table 9. Pellet Production Expenses: Energy, Time and Cost

\section{Model Results}

\section{First subheading}

As it can be seen from Table 10, the results for investing in a mobile pelletizer (MP), moving it and producing pellets with it, and then moving the pellets to the distributors (Ds) (Case A) have the the following total yearly values and specific values per ton pellet of the different alternatives:

\begin{tabular}{|c|c|c|c|c|}
\hline \multirow[t]{2}{*}{ Criteria } & \multirow[t]{2}{*}{ unit } & \multicolumn{3}{|c|}{ Cluster Size } \\
\hline & & "S" & "M" & "L" \\
\hline \multicolumn{5}{|c|}{ Total values of pellet production and transport } \\
\hline Energy & $\operatorname{kg} \mathrm{CO} 2$ & 218585 & 292116 & 292060 \\
\hline Time & $\mathrm{h}$ & 4601 & 5383 & 5381 \\
\hline Cost & $€$ & 251523 & 313316 & 313131 \\
\hline \multicolumn{5}{|c|}{ Specific values of pellet production and transport (per ton pellet) } \\
\hline Energy & $\operatorname{kg} \mathrm{CO} 2$ & 291,4 & 289,8 & 289,7 \\
\hline Time & $\mathrm{h}$ & 6,1 & 5,3 & 5,3 \\
\hline Cost & $€$ & 335,4 & 310,8 & 310,6 \\
\hline
\end{tabular}

Table 10. Supply Chain Results for Pellet Production and Transport - Case A

Table 11 shows the total and the specific results of the cluster size alternatives for moving the wool bales, producing pellets with pellet factories (PFs) and moving the pellets to the distributors (Ds) (Case B).

\begin{tabular}{|c|c|c|c|c|}
\hline \multirow[t]{2}{*}{ Criteria } & \multirow[t]{2}{*}{ unit } & \multicolumn{3}{|c|}{ Cluster Size } \\
\hline & & "S" & "M" & "L" \\
\hline \multicolumn{5}{|c|}{ Total values of pellet production and transport } \\
\hline Energy & $\mathrm{kg} \mathrm{CO} 2$ & 233578 & 462893 & 1146853 \\
\hline Time & $\mathrm{h}$ & 2852 & 5520 & 13352 \\
\hline Cost & $€$ & 224284 & 434400 & 1051504 \\
\hline
\end{tabular}




\begin{tabular}{|l|l|l|l|l|}
\hline \multicolumn{5}{|l|}{ Specific values of pellet production and transport (per ton pellet) } \\
\hline Energy & kg CO2 & 311,4 & 308,6 & 305,8 \\
\hline Time & h & 3,8 & 3,7 & 3,6 \\
\hline Cost & $€$ & 299,0 & 289,6 & 280,4 \\
\hline
\end{tabular}

Table 11. Supply Chain Results for Pellet Production and Transport - Case B

\section{Discussion}

The model results have shown, that with increasing cluster sizes and pellet sales also the specific values for energy, time and costs of the production and distribution of one ton of pellets have slightly decreased in Case B. This was not true for Case A, since the mobile pelletizer unit reached its maximum capacity at cluster size " $M$ ", thus, further increase in the number of cluster participants and inputoutput possibilities has not increased the returns on the mobile unit's investment. Furthermore, lack of the mobile units investment for Case B was a balancing factor also in the smallest cluster size in the model, even when considering the surplus in wool transport, which was not needed in Case A.

\section{Conclusion}

Model calculations have supported the conclusion that investing in a mobile unit is questionable even in case of a small cluster size, and with growing cluster sizes, advantages of involving existing pellet factories became evident.Based on the given preliminaries, evaluation of the model results has supported the recommendation to choose case B) for further technology and supply chain management decisions.

\section{References}

[1] Project proposal (2012), Market Umbrella for the utilisation of low grade grease sheepwool as organic soil amendment and fertiliser - Value4Wool CIP Eco-innovation First Application and market replication projects Call 2011, ifn GmbH, Lauchhammer

[2] T. Lützkendorf (2014), Bachelor-Arbeitzum ThemaErstellung einer Ökobilanz (LCA) für ökologischen Langzeitdünger "floraPell ${ }^{\circ}$. (Bachelor thesis on the subject of the compilation of a life cycle analysis (LCA) for the ecologic long term fertilizer "floraPell ${ }^{\circ}$ “.), Supervisors: Prof. Dr.-oec. Hubertus Domschke, Dipl.-Ing. Rolf Herkner, University of Applied Sciences Fachhoch schule Lausitz

[3] Product documentation „floraPell@“- Der ökologische Langzeitdünger aus Schafschurwolle. („floraPell®" - The ecologic long term fertilizer from sheep wool.) Product documentation.http://florapell.de/download.php?datei=florapell_dokumentation.pdf 